\title{
Perceived Social Support and Severity of Chronic Pain in Fire Fighters of Tehran City
}

\author{
Mohammad Kianbakht ${ }^{1}$, Sedighe Naghel $^{2}$, Hossienkohandel ${ }^{3}$, Vida Namdari ${ }^{4}$
}

\section{ABSTRACT:}

Objectives: The main goal of the study was to investigating the relation between perceived social supports with severity of chronic pain in fire fighters of Tehran city.

Method: this was a descriptive and correlational study. Accordingly, 400 fire fighters were selected through cluster random sampling. All subjects filled chronic pain questionnaire and multidimensional scale of perceived social support (MSPSS). Data was analyzed through Pearson correlation coefficient and linear regression.

Results: results showed that there is significant and negative relationship $(p<0 / 0001)$ between severity of chronic pain with perceived social support and its' aspects (supports from family, friends and important persons).

Conclusion: findings of this study again demonstrated the important role of socio-psychological factors in predicting severity of chronic pain.

Keywords: social support, chronic pain, socio-psychological factors

Chronic pain is the phenomena which its' recovery takes more than usual and expected time. According to International Association for the Study of Pain this recovery period is set up 3 month for research targets and 6 months for academic targets (Thron, 2004). Turk and Okfuji (2001) found that patients with the same diagnosis and same therapy, showed different responses. Accordingly, only evaluating intensity of pain is not enough, the more important is to evaluating mood, related beliefs of pain, coping strategies, quality of life, physical disability, attitudes of patient toward life and more generally effects of pain on patient's life. Moreover, human is a social animal that has complicated connections with environment, but chronic pain change the relationship and these connections with others, immensely.

\footnotetext{
${ }^{1} \mathrm{Ph} . \mathrm{D}$ student of clinical psychology, Department of Psychology, Aligarh Muslim University, INDIA. ${ }^{2}$ M.A. of General Psychology, AllameTabatabai University Tehran, Iran.

${ }^{3} \mathrm{Ph} . \mathrm{D}$ student of clinical psychology, Department of Psychology, Aligarh Muslim University, INDIA. ${ }^{4} \mathrm{Ph} . \mathrm{D}$ student of clinical psychology, Department of Psychology, Aligarh Muslim University, INDIA.
} 
Mutually, relationship quality of patient with others influences on chronic pain. Therefore, it is significant to study chronic pain in its' own context. As mentioned above, it is improbable to consider all chronic pain patients identically, even with the equal medical diagnosis. Accordingly, Waddell (1987) mentioned professions who works with chronic pain patients and wrote: "We must consider low back pain as an illness rather as disease. We all recognize in theory and need to consider physical, psychological and social aspect of illness". In other words, we need to reconstruct new format for any patient and not just recognition according to locus of pain and diagnosis. Cohen (2004) has defined social support as following: social support is a social network which provides psychological and tangible resources for people to cope with stress and problems of life. When the pain continues, patient shows Anger, frustration and avoidance as behavioral indicators in relationship with others. He maybe realizes that there is some problem in talking with others and can't talk logically in social situations like work place.

It is hard to say no against requests probably, which leads to ambivalence, Annoyance of others and unable to meet their demands and have to deposit them. Others may feel doubt and rejection from him. This can increases the problem and disrupt the relationships. According to evidences, in a twosome relationship which one has chronic pain, origins of the most conflicts are from this person with his behavioral indicators. It is rather, because his approaches about the situation, which if change others will be change also. The chronic pain patient may be unable to change and handle people, but he should try to manage own behavior. Some possible behaviors of a patient with chronic pain are listed below. Regardless of how behavior starts, he must concentrate whether he perform this behaviors while feeling pain or not? Such behaviors have an important role to receiving perceived social support (Nicolas, Molloy, Tonkin, \& Beeston 2012). In one prospective study, Iman, Walter and Jeffrey (1993) studied first back pain experience among New York city fire fighters. 109 subjects were selected randomly, and studied during around one year (1988-89).

According to their results factors that lead to back pain (with controlling out of work activities) were as follows: carrying tubes into buildings, climbing the ladder, breaking the windows, searching hidden fires in place, lifting objects heavier than $18 \mathrm{Kg}$. on the other hand, other low risk factors that leads to back pain including connecting pipes to pumps, pulling pipes, activities with drill machines, physical activities and exposure to fume from burning flammable materials. This experiment performed in a controlled condition, whereas in normal conditions, urgent for attending in event place and exposure with real condition may leads to more severe back pain.

\section{METHOD}

\section{Participants}

Statical society included all fire fighters in Tehran city which was approximately 3600 persons. Subjects were selected through cluster random sampling so that 30 fire stations were selected from 120 ones. Finally 400 fire fighters were selected randomly as sample of study. The mean and standard deviation of the ages were $92 / 32$ and 63/6. $75 \%$ were married and the rest were 
single. 31/2 suffered from chronic pain with different severity and 68/8 had no sense of pain. It comprised several Iranian races including 45\% Persian, 38/3 \% Azeri, 0/12\% Lor, 4/3\% Kurdish, and $0 / 1 \%$ Arabian. The mean and standard deviation of pain history (months) totally were $17 / 54$ and $26 / 87$, and in patient with chronic pain were $56 / 13$ and $11 / 83$. It showed clearly the presence of chronic pain in the sample.

\section{Tools}

Graded chronic pain questionnaire (AsghariMoghadam 1997, 2011): It includes 42 items which is not only allocates to recognize and navigation of pain, but also evaluates several aspects of pain. This questionnaire identifies severity of Pain, locus of pain, continuity of pain, pain-related disability, pain history, pain-related behaviors, emotional states of patients, causes of pain and interpersonal relationships. As well as, it determines that how many times the patients have referred to hospital or other medical places. With this questionnaire not only it is practicable to recognize chronic pain patients but also it is possible to classification of patients according to severity of pain.

In one study (Asghari Moghadam, Karami and Rezaie, 2011), calculated the internal consistency coefficient graded chronic pain scale with research data and results showed appropriate internal consistency coefficient for this questionnaire (Cronbach's alpha coefficients: 0/83). In this study, Cronbach's alpha coefficient was used to check the reliability of the questionnaire and obtained Cronbach's alpha coefficient was $0 / 88$ for the total scale.

Multidimensional Scale of Perceived Social Support (MSPSS): The MSPSS was developed by Zimet, Dalhem, Zimet, \& Farley (1988) and aims to measure perceived social support. It includes 12 items which cover three dimensions; Family, Friends and Significant others. Each item is rated on a seven-point Likert-type response format $(1=$ very strongly disagree; 7 = very strongly agree). A total score is calculated by summing the results for all items. The possible score range is between 12 and 84, the higher the score shows higher the perceived social support (Ekbäck, Eva, Lindberg and Årestedt, 2013). In addition, separate subscales can be used by summing the responses from the items in each of the three dimensions. The possible score range for the subscales/dimensions is between 4 and 28 (Zimet, Powell, Farley, Werkman, Berkoff, 1990). The MSPSS is widely used and the three-factor model has demonstrated good psychometric properties in previous studies. There is less evidence available for the one-factor model.

It takes just 3 minutes to complete this questionnaire and it is a good advantage of this scale. According to Zimet, et al (1988), Alpha coefficient was between 0/85-0/91, and with retest is reported between 0/72-0/85. Salimi et al. (2009) obtained reliability of this scale in Iran. Results showed 3 subscales which there are 4 items for each of them and KMO was 87\%. Cronbach's alpha coefficient for the three dimensions of perceived social support (family, friends and other important people) were 0/86, 0/86, 0/82 respectively. In this study, Cronbach's alpha coefficients 
for the three dimensions of perceived social support (important people in life, family support and friend support) were 0/90, 0/93, 0/91 respectively. Cronbach's alpha coefficient obtained for the total scale was $0 / 95$.

\section{RESULTS}

Table: Simple correlation matrix between the variables, the mean and standard deviation of the total sample

\begin{tabular}{|l|l|l|l|l|l|}
\hline variables & 1 & 2 & 3 & 4 & 5 \\
\hline Severity of chronic pain & 1 & & & & \\
\hline Perceived social support & $-0 / 43^{* *}$ & 1 & & & \\
\hline Supports from important persons & $-0 / 44^{* *}$ & $0 / 93 * *$ & 1 & & \\
\hline Supports of friends & $-0 / 39^{* *}$ & $0 / 90^{* *}$ & $0 / 69 * *$ & 1 & \\
\hline Support of family & $-0 / 38^{* *}$ & $0 / 94^{* *}$ & $0 / 87 * *$ & $0 / 76^{* *}$ & 1 \\
\hline Mean & $0 / 80$ & $65 / 39$ & $21 / 94$ & $20 / 40$ & $23 / 05$ \\
\hline Standard deviation & $1 / 25$ & $17 / 16$ & $6 / 35$ & $6 / 30$ & $5 / 85$ \\
\hline
\end{tabular}

$* * \mathrm{P}<0 / 001$

According to table, perceived social support and its' aspects (perceived support of important persons, friends and family) has a negative correlation with severity of chronic pain $(\mathrm{P}<0 / 001)$. As well as, results of linear regression showed that perceived social support explained 19\% of variance of severity in chronic pain $(\mathrm{F} 1,308=94 / 396, \mathrm{P}<0 / 001)$. The higher Severity of pain correlated with lower perceived social pain.

\section{DISCUSSION}

Results of this study showed there is negative correlation between severity of chronic pain with perceived social support and its' aspect (perceived social support from family, friends and important persons). In other words, the person with higher rate of chronic pain experienced lower rate of social support (in all aspects). This result is consistent with Alicia \&López-Martínez (2008) and Davoudi, et al (2012). According to result of this study and other studies such as Bisschop, et al (2004), it's been explaining that social supports from important persons of life, family and friends improve psychological wellbeing through satisfying personal needs like sense of attachment and belonging, and therefore coping with Loneliness. As well as, resources of social support can be a shield against the chronic pains by enhancing compliance with treatment recommendations and psychological adjustment which finally lead to recovery.

Results of this study, also, provide more empirical evidence that reveals the importance of biological-psychological-social model, for understanding chronic pain patients and chronic pain therapy. It can be concluded low perceived social support is a peril factor in adjustment with 
chronic pain disorder (adjustment with its' severity and inability). Therefore, regarding important role of socio-psychological factor including perceived social support and its' aspects, it is recommended to take these factors into account at Health centers.

Finally, regarding society of this study (fire fighters) it is important to be caution about generalizing the results. Moreover, since it was a correlational study it is important to conduct an interpretation between variables. It is recommended to evaluate other socio-psychological variables and also other societies for further research. As well as, it is recommended to measure effectiveness of socio-psychological factors at this relationship, using therapeutic approaches such as family therapy, couple therapy, and improving interpersonal social skills.

\section{REFERENCES}

AsghariMoghadam, M, A. (2011). Pain and its' measurements: new perspectives in psychology of pain. Roshd publication.

Asghari-Moghadam MA, Karami A, Rezaee S. (2002). Prevalence of pain in life, chronic pain and continued with some of its characteristics. J Psychol, 1, 30-51.

Davoudi, I. Zargar, Y. MozafariPorsiSakht, E. Nargesi, F. Mola, K. (2012). The relationship between pain catastrophizing, pain anxiety, neuroticism, social support and coping with functional disability in rheumatoid arthritis.Educational science and psychology. 1, 1-15.

Alicia E. López-Martínez (.2008). Perceived Social Support and Coping Responses Are Independent Variables Explaining Pain Adjustment Among Chronic Pain Patients, The Journal of Pain. Volume 9, Issue 4, Pages 373-379.

Bisschop, M. I.; Kriegsman, D. M. W.; Beekman, A. T. F. \&Deeg, D. J. H. (2004), Chronic diseases and depression: the modifying role of psychosocial resources, Social Science \& Medicine, 59, 721-733.

Cohen, S. (2004). Social relationships and health.American Psychologist, 59, 676-684.

Ekbäck, M., Benzein, E., Lindberg, M., \&Årestedt, K. (2013).The Swedish version of the multidimensional scale of perceived social support (MSPSS)-a psychometric evaluation study in women with hirsutism and nursing students.Health Qual Life Outcomes, 11(168), 1477-7525.

Iman A. Nuwayhid1, Walter Stewart and Jeffrey V. Johnson.(1993). Work Activities and the Onset of First-Time Low Back Pain among New York City Fire Fighters. Am. J. Epidemiology. 137 (5): 539-548.

Nicholas, M., Molloy, A., Tonkin, L., \& Beeston, L. (2012). Manage your pain: practical and positive ways of adapting to chronic pain. Souvenir Press.

Salimi A, Jowkar B, Nikpour R. (2010). Internet and communication: perceived social support and loneliness as antecedent variable. $Q J$ psychol stud.5(3).81-102, [Persian].

Thron. BE. (2004). Cognitive therapy for chronic pain: step by step guide. New York: Guilford Press; 21-165. 
Turk, D. C., Okfuji, A., (2001).Matching treatment to assessment of patients with chronic pain. In: Turk DC, Melzack R, editors. Handbook of pain Assessment $2^{\text {nd }}$ Ed. New York: Guilford press, pp. 400-414.

Waddell G. (1987). A new clinical method for the treatment of low back pain.Spine, 12, 632644.

Zimet, G.D., Dahlem, N.W., Zimet, S.G. \& Farley, G.K. (1988).The Multidimensional Scale of Perceived Social Support.Journal of Personality Assessment, 52, 30-41.

Zimet, G. D., Powell, S. S., Farley, G. K., Werkman, S., \&Berkoff, K. A. (1990).Psychometric characteristics of the multidimensional scale of perceived social support.Journal of personality assessment, 55(3-4), 610-617. 